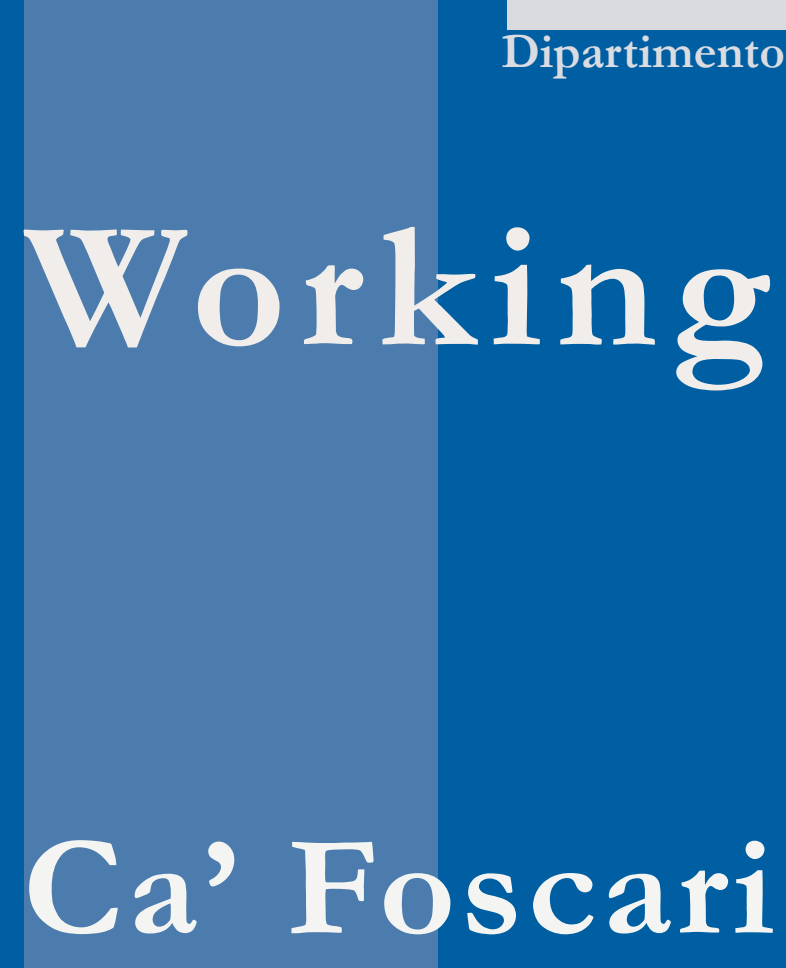

Scienze Economiche

Paper

Department

of Economics

University of

Venice

Jan van der Borg

Erwin van Tuijl

Alessandro Costa

Designing the Dragon or does the Dragon Design? An Analysis of the Impact of the Creative Industry on the Process of Urban Development of Beijing, China 


\title{
Analysis of the Impact of the Creative Industry on the Process of Urban Development of Beijing, China
}

Designing the Dragon or does the Dragon Design? An

\author{
Jan van der Borg \\ Ca' Foscari University of Venice \\ Erwin van Tuijl \\ Erasmus University Rotterdam
}

Alessandro Costa

Sino-Italian Cooperation Program for Environmental Protection

\begin{abstract}
After reading Richard Florida's work (e.g. Florida, 2003) on the creative industry and on the importance of the creative class for urban development in post-industrial economies, many cities in Europe and the USA have started to invest in creativity in general and in design in particular. Much less is known about the role of creativity in industrial economies (Pratt and Jeffcutt, 2009). This paper analyses the role of design in the economic and social development of China's political and cultural capital Beijing. We will try to identify the main success factors and barriers for the design business and show how design can be further used for social and economic development of the city. Backed up by conspicuous state investments and by fast decision making, industrial areas have been transformed and neighbourhoods have been revitalised, infrastructure has been upgraded, and some modern iconic landmarks are added to the collection of old monuments. Moreover, priority has changed from "Made in China" to "Create in China", allowing economic activities to move upwards in the value chain. Nevertheless, and despite the presence of key research and art institutes, further developments of the design sector and the use of design in other (manufacturing) sectors will still be a huge challenge.
\end{abstract}

Keywords Creative Industry, Design, Urban Development, Industrial Economy, Beijing, China

JEL Codes P21, R11, R30, R38, R53, Z11

Address for correspondence:
Jan van der Borg
Department of Economics
Ca' Foscari University of Venice
Cannaregio 873, Fondamenta S.Giobbe
30121 Venezia - Italy
Phone: (++39) 0412349135
Fax: (++39) 0412349176
e-mail: vdborg@unive.it

This Working Paper is published under the auspices of the Department of Economics of the Ca' Foscari University of Venice. Opinions expressed herein are those of the authors and not those of the Department. The Working Paper series is designed to divulge preliminary or incomplete work, circulated to favour discussion and comments. Citation of this paper should consider its provisional character.

The Working Paper Series is availble only on line www. dse.unive it/pubblicazion For editorial correspondence, please contact:wp.dse@unive.it
Department of Economics

Ca' Foscari University of Venice Cannaregio 873, Fondamenta San Giobbe 30121 Venice Italy

Fax: ++390412349210 


\section{Introduction ${ }^{1}$}

China is one of the oldest civilisations in the world and therefore possesses a long history in art and culture. Although its material aspects have been neglected until recently, the country is very rich in cultural heritage: numerous palaces, temples and other religious and political works dating many ages back. Art and culture have always played a major role in economic and social development. To give an example, Mao announced in 1942 that arts should serve the people, meaning in fact the working class and soldiers (Chen, 2007).

Since the economic reforms in 1978, China has gradually opened to the world and has developed rapidly. The average annual growth of GDP between 1978-2005 was 9.6\% and in terms of economic size it has become the fourth largest country in the world after the United States, Japan and Germany (Holz, 2008). However, China is still in the middle of a process of industrialisation, not yet needing to diversify its economy as urgently as many countries in Northern America, WesternEurope and Japan. Remarkably, this has not hindered the city of Beijing to focus on culture and creativity as a powerful means to revitalise and to modernise parts of its urban economy. Moreover, it has already started to consider, although it still is competitive merely for its low costs of production, the decisive role culture and design can play in moving upwards in the global value chain, towards activities that provide more added value and profit margins.

Economic development has thus a number of important consequences for the development of creative industries in general and design in particular. First, due to rising income, especially in the big cities such as Beijing and Shanghai, there is a rising demand for art (aesthetical design) and new forms of art enter the Chinese market. Especially the demand and the supply of contemporary art, which was unknown in formal markets until the end of the 1990's, have risen quickly. This was one of the principal explanations of the growth of the 798 District, one of the biggest clusters for contemporary art in China. Second, China's entrance in the WTO has led to increased political awareness for culture and creativity. In fact, culture has always been recognised as a fundamental ingredient

\footnotetext{
${ }^{1}$ The authors like to thank the Institute for Housing and Urban Development Studies of the Erasmus
} University Rotterdam for its financial contribution to the research on which this paper has been based 
of economic development and was quickly put on the national political agenda in the period leading to the WTO accession (Keane, 2009). The creative industries were officially put on the agenda in the $11^{\text {th }}$ Five Year Plan in 2005 (Rossister, 2008a). An important goal within the $11^{\text {th }}$ Fifth Year Plan is the ambition to change from 'Made in China' to 'Create in China', and thus to move higher up the value chain On the local level, creative industries got some first attention in Shanghai in the beginning of 2004, while the start of the Shanghai Creative Industry Centre marked the fact that creativity had become a political priority of in January 2005 by. Beijing started the development of 10 'creative cultural' clusters slightly later in December 2006 (Keane, 2009).

Another major event leading to an increased attention to and the development of design were the Beijing Summer Olympics in 2008. As in many other hosting cities, the Olympics were used as a flywheel for urban development, also by paying much attention to the design, that is indeed spectacular, of new iconic landmarks (e.g. CCTV Tower and the National Stadium, better known as the 'birds nest') and the improvement and revitalisation of various areas in the city. One of these improved areas of the city is the already mentioned and emblematic 798 District, that plays an important role in this paper. Moreover, the Olympic Games have been used to increase awareness of the development of a green society which has led to an increasing attention for 'sustainable design' (the use of design for sustainable development).

This paper intends to investigate the role of design in Beijing, the political and cultural capital of China, in all its aspects. We focus therefore on the various types of design: design as an economic activity (and hence as part of the creative sector) and creative clusters, design as an art form (aesthetical design), and urban design. We have investigated the success factors and barriers for design business in Beijing and give policy recommendations in order to improve the conditions for social and economic development of the city.

The material on which this paper is based was gathered during a visit of the city in May 2009. During this visit, 20 in-depth interviews were held with key-actors of Beijing's creative industry and policymakers.

The rest of this paper is structured as follows. Section 2 analyses the major geographical concentrations for design activities (with special attention to the 798 District) and section 3 describes the major spatial economic conditions that 
Beijing currently offers for the development of the design sector and other creative industries. The subsequent section 4 deals with urban design, while section 5 focuses on aesthetical design. In section 6 , the attention goes to the governance and policy of design activities. The last section 7 draws some conclusions and provides a number of policy recommendations.

\section{Geography: Creative clusters in Beijing}

Although cultural and creative activities are spread across all districts in Beijing, and despite the relatively meagre presence of cultural heritage due to a structural reflectance of the material dimension of heritage until recently, the Chaoyang District has been designated as a development base for the creative industries. It has several important assets to attract creative business (Hui, 2006).

First, the district serves as the new commercial centre of the city with the Central Business District (CBD), the Olympic Village and the new airport in the northwest of the city as major locations providing several advantages for the development of creative industries. The CBD hosts many embassies (only two embassies are not in the district), several headquarters of foreign companies (two third of the global 500 companies are setting up headquarters in the CBD); its hotels and bars provide a vibrant, international urban environment that might be inspiring for designers. Moreover, the location of the headquarters and other business increases the demand for services from certain creative industries, such as media and advertising and the presence of (foreign) employees with high income stimulates the demand for cultural goods and services. In addition, the CBD and Olympic area have several modern landmarks that enhance the district's image as 'modern and trendy city' in China and might stimulate Chinese architects to focus on modern architecture.

Second, the relocation of the CCTV, Beijing TV and Phoenix TV headquarters has increased the critical mass for the development of media industries;

Third, the district is home of various knowledge institutes that are specialised in certain creative industries, such as the Academy of Design of Tsinghua University, the Communication University of China, Beijing Institute of Clothing Technology, the Arts and Design Department of Beijing Union University and the Central Academy of Fine Arts. These institutes form a major basis for the development 
of the creative industries and might attract industries around them;

Fourth, various cultural festivals, like the Chaoyang International Pop Music Festival and the 798 Art Festival have been organised in the district, which enhances the image of Chaoyang as a creative district.

In sum, the Chaoyang offers numerous location factors that explain its attractiveness for creative industries; in fact, many of creative clusters that are discussed in more detail in this section are indeed to be found in this district.

There are (at least) two types of creative clusters in Chaoyang and in other districts in Beijing: 'artists' creative clusters and 'commercial' creative clusters. Artists creative clusters appear and grow 'spontaneously' by initiatives of artists who decide to concentrate in a certain area to benefit from the economies of clustering such as a shared labour pool (e.g. Porter, 1998) and 'buzz', an information and communication environment created by co-presence and face-to-face contacts between various cluster actors (e.g. Venables and Storper, 2002; Bathelt et al., 2004). Commercial creative clusters are driven by real estate speculations and are much more planned, focussing on commercial spin-offs of art and culture.

In the reminder of this section we first give a description of the history and development of 798 District that has developed from an artist to a commercial creative cluster. Second, we describe other creative clusters in Beijing and compare and contrast these various districts and analyse the dynamics between the districts. Based on the empirical analysis of 798 District and the other districts, we also give characteristics of the two types of creative clusters as we have distinguished.

\subsection{Art District}

The 798 Arts District (or Beijing Dashanzi Arts District) in the north eastern Chaoyang District of has transformed quickly from an artist cluster to a commercial cluster. In the past, the district was a state-owned electronics firm that also produced equipment for the military industry (and hence the mere number as indication of the area). It was set up with help of the communist regime in East-Germany and was built in Bauhaus style. It has grown into a commercial art district in three stages: the pre-2006 period, 2006-2008 and $>2008$, which are discussed in more detail in the rest of this section. 


\section{$<2006$ Artist creative cluster}

798 Arts District started as an artist creative cluster by the spontaneous arrival of various artists and gallery owners that used empty spaces of the production site as galleries and working studios. The plant was still largely in operation, but was targeted to be demolished in the near future. Meanwhile empty spaces were rent out to artists who benefited from low rents. The first artists settled down in the area in 2000-2002. They were attracted by the low rent and the creative surrounding of the old production plant. The presence of workers combined with the Bauhaus style architecture created an inspiring atmosphere. The number of artist grew rapidly, since artists asked friends to come and created an informal community gathering at places such as in a bookshop. The first artist entered in 2000 and by the end of 2001 about 15 artists lived in the area. In 2002, Tokyo Gallery, under the name Beijing Tokyo Art Projects (B.T.A.P.) entered the factory and in 2003 the district counted six galleries. It is worth noting that both Chinese as well as foreigners were attracted to the place.

The artists and gallery owners organised various joint events such as exhibitions, concerts, and seminars. A major event was the Danshanzi International Art Festival (DIAF) which was organised to create a platform for Chinese contemporary art and for other creative industries such as film. The festival was set up quickly in order to get more (media) attention in order to prevent that the plant would be demolished.

\section{6 - 2008 Transition from artist to commercial creative cluster}

In 2006, the Beijing 798 Art Zone Administration \& Development Office (in short 798 Management) was set up in order to serve as a bridge between the tenants and the owner of the district, Seven Star Group, a company that is part of a large state-owned conglomerate. The board of administration of 798 Management consists of representatives of Chaoyang District, the Propaganda Department and the Bureau of Tourism and is headed by a representative of Seven Star Group. The management in cooperation with the Seven Star Group and the local government decided not to demolish the plant and to focus on the exhibition and sales of contemporary art.

The 798 Arts District grew rapidly during this period and in 2008 the district counted already 150 galleries. One of the new entrants in this period was the Ullens Center for Contemporary 
Art (UCCA), the biggest organisation ( 85,000 square-foot) of the district. The entrance of UCCA is considered as a major step to guarantee the future of the district (Chen, 2007). Moreover, the district increasingly receives international (media) attention, among others through various articles published in foreign news papers and magazines (e.g. in 2007 articles dealing with the district were published in the Los Angeles Times and in the Economist), and by visits of foreign policy makers.

The quick growth has also an important down-side in the form of rising rents, and the district transforms rapidly from an artist creative cluster to a commercial creative cluster. The increasing rents push artists to other clusters and their studios are replaced by commercial galleries. It has been argued that only the most successful artists can afford to pay the higher rents and will stay in the area. Also the audience changes from real art 'freaks' to 'normal' tourists with limited knowledge about real art. In relation with this, real art disappears to make place for more commercial products. Moreover, the creative atmosphere of the area disappears; the remaining production plants close down and commercial galleries and secondary tourist products, such as hotels and restaurants are opened. Finally, there exist tensions between the 798 management and tenants. There are doubts about the bridging role of the management between the tenants and the Seven Star Group, and it has even been argued that the management actually responds principally to Seven Star Group. In addition, there are some complaints among the tenants for the actions taken by the management and already some artists left because of the increasing rents and different interests. For instance, one of the tenants had suggestions for improving the landscape of the area. The management did not agree and immediately stopped the contract of this tenant. Another action of the management that was not appreciated by the tenants was that it prohibited the DIAF and started in a later stage the 798 Art Festival, according to many a simple and less interesting copy of the DIAF festival.

\section{$>2008$ Further development of commercial creative cluster and tourism}

In the current development stage, the transition to a commercial creative cluster and a tourist attraction continues. This was speeded up by the Olympic Games. In January 2008 the district was appointed as an official spot for the Olympics and only a few weeks before the Olympics the area was upgraded intensively. Public art works were placed on the streets, public lightening was installed and green spaces were 
created in order to improve the urban landscape. In addition, the closure of the production plants has continued and it is expected that by 2010, there are no plants in operation anymore. This is considered to be a major loss for the creative atmosphere in and in the identity of the area.

At the moment of writing, the district counts over 350 art institutes, which are active in different sectors: culture and art (140 institutes), design and consultancy (including architecture, fashion and interior design; 100 institutes), media (magazines, TV and music; $70-80$ ) and tourism (bars and restaurants; 13). This diversity has been considered as an advantage since the various fields of design can reinforce each other and has potential synergies between the different fields. Nevertheless, nearly all our conversation partners agree that the district is too commercial. Similarly, Muynck (2009) states that the 798 Arts District destroyed the sources of creativity by its own success and that the art fabric changed to an art market. Rossister (2008) notes that creative clusters in China, such as 798, should be paid of in terms of intellectual property rights, but that in reality these clusters seems to drive up real estate prices. It should be mentioned that the role of real-estate speculation is common in creative industries in all parts of the world (Rossister, 2006) and many industries within the creative sector are characterised by tensions between cultural and commercial interests.

The management of 798 is aware of the increasing real estate prices and the departure of artists to other clusters. Financial support from the municipality is badly needed to keep the less commercial artists. Another solution might be to ask (foreign) galleries to invite artists to produce art in the district as showcases.

For the future development, the district has been targeted as a key area to show Chinese art with the focus on sales and the exhibition of Chinese art. It is the major cluster that combines 'East with West' and the aim is to connect Beijing with the rest of the world in order to promote Chinese art. Currently, about $15 \%$ of the tenants comes from abroad while $85 \%$ is Chinese. The foreigners come from various countries. The ambition is to attract more famous foreign art companies and to increase the total number of Chinese companies. Moreover, the concept has been used by the local government and uses it as a best practice for the revitalisation of obsolete industrial areas and the development of other art districts. Another ambition is to become a top tourist attraction just like the Tiananmen Square and the Summer Palace. 
Currently, the district is not yet considered as an official tourist destination by the Municipality of Beijing, despite the fact it was identified as an official spot for the Olympics. The recognition as an official spot could be interesting for the City of Beijing to diversify its tourist product, from attractions linked to its traditional cultural heritage to modern icons and spots, which is one of the main goals of the recent tourism development strategy that the city of Beijing is trying to implement. This could also increase the number of foreign tourists, which are interested in both cultural heritage, such as the Forbidden City and the Summer Palace, as well as in modern attractions. For the moment, this is in contrast to what Chinese tourists aim for. In fact, they mainly come to Beijing to visit the traditional cultural attractions.

\subsection{Other creative clusters and a comparison with 798}

Clusters rise and fall and artists move from one cluster to the other in case of rising real estate prices or actions by policy makers. These spill-over effects are not necessarily bad, as long as the revitalisation of obsolete urban areas results to be sustainable. This is also the case of Beijing which has numerous creative clusters. Two of the first creative clusters in Beijing were Yuanmingyuan, near the old ruins of the old Summer Palace in the north of the city, and Dong Cun, or East Village. Both districts were artist creative clusters spontaneously developed by the artists themselves, enjoying the creative surrounding away from the city centre and the policy makers. This was important, since until the end of the 1990's, art was under strict censorship (Rui, 2008). Nevertheless, in 1994 respectively 1995 the clusters were forbidden by the government and the police raided the artists (Pasterneck, 2008).

Nowadays, there are several creative clusters, including both artist creative clusters arisen on new locations where artists have settled down as well as commercial creative clusters often stimulated by the government which use creative clusters as new policy tool to realise economic growth. Initially, and in contrast to Shanghai, which directly opted for setting up numerous creative clusters, the Beijing government focussed on ten creative clusters. However, in 2008, probably also due to the Olympics, this number has risen quickly (Keane, 2009). In this section we first discuss the major creative clusters in Beijing before comparing them with 798 Art District. 
D-Park (or 751 District) is located directly next to the 798 District and focuses on fashion design and architecture. The views about D-Park are mixed. Some perceive the D-Park as less commercial than 798 District and have doubts whether it can survive without commercial activities. Also the atmosphere has been perceived as more creative by the restoration of old plants in original style. Others argue that D-Park has been rebuilt as a tourist district. Many reconstructed 'attractions' are replicas of the originally buildings and machines and sometimes these are placed at other places than the original ones. For instance, the train station has been restored next to the main road that connects 751 D-Park with 798 district. It should be noted that 751 District is led by another management and that there is no cooperation between both managements. Furthermore, it is worth mentioning that the reconstruction plan was made in cooperation with a local university and university professors and architects contributed to the design of the district.

Songzhuang Art Village is a big artist community with over 1,000 artists who are focussing on the creation of temporary art. Many produced works are directly sold to the international art market and the village has several galleries to show art works. Keane (2009) notes that many artists in Songzhuang produce original works in order to sell it to art galleries and museums in China's big cities. In addition, he notes that tax is relieved on paintings sold in exhibitions and auctions, which gives prestige to local officials despite the fact that the revenue directly goes to the national and city governments. Pasterneck (2008) mentions that the local government used tax incentives and cheap land to attract artists. For instance, in 2006 it spent more than $\$ 1.3 \mathrm{M}$ on an art centre in the district. The art village is located in the northwest of the city, about 80 $\mathrm{km}$ from the city centre.

Huantie Art District is located in the loop of a railway testing track near 798 District. It has been considered as less touristic and commercial than 798 and is more calm. Artists live in former storage sites for railway goods and rents are relatively low. Due to the fact that the railway testing track is still fully in operation, it is difficult to enter the area which creates a calm and creative atmosphere. Many artists create art works in 
Huantie and sell these in 798 District. The number of artists and organisations that enter the district is steadily rising.

Cao Chang Di Art Village is an art cluster that has been set up by the local government. The village counts over 20 galleries and/or studios and more artists have announced to come. The cluster is located in the north west of the city in the Chaoyang district in proximity of 798 District.

Jiuchang Art District is located close to the Central Academy of Fine Arts (CAFA) in the Chayang district near 798 District. The district started in 2006 and the Korean Arario Gallery was the first one to enter. Many other organisations followed and various CAFA professors set up their own studio in the district after returning from abroad. The location in the former Chaoyang winery contributes to a creative atmosphere. Besides attention to aesthetical design, the area focuses also on graphical design, as it houses the core development centre for the Chinese cartoon making industry.

Suojiacun, Feijiacun and Art Base 1 are districts which house mainly art studios. The rents are lower than in 798 and the districts have a quiet, but inspiring surrounding.

Cable 8 is a remaining industrial area in the Central Business District of Beijing that changed from an old electronic cable factory to a new media cluster in 2007 . The management of the factory is still the old management which decided to stop production and to rent out spaces to multimedia designers, fashion designers, architects and other creative companies. The total factory covers $22,000 \mathrm{~m}^{2}$ and 8 buildings and already 160 companies are located in it.

Ban Qiao Hutong and Dong Si Hutong, both perpendicular to more famous Dong Bei Da Jie Hutong, are forming a creative cluster in the old part of the city centre of Beijing. Various architects and other designers have located their studio in this area because of low rents and the creative surroundings. The location among the people in the middle of the city centre creates an inspiring atmosphere. Even successful Chinese architects with an international breakthrough and foreign architects who can afford to pay higher rents prefer staying in the Hutong clusters for the vibrant surrounding, the original 
'roughness' and good public transport connections. In addition, the architects benefit from the co-location of other architects and designers. Despite this, joint business projects are limited and potential synergies are not realised. However, the actors in the cluster have strong informal networks in which they share and transfer information about various topics such as the availability of human capital on the local labour market. The cluster is based on grassroots development and the government is not involved. However, there are fears that government involvement might take place in the future and that real estate prices will be driven up crowding out the designers as it has happened in other clusters such as the 798 District.

As the description of these clusters has made clear, there are numerous important differences between 798 District and the other districts. First, most other districts are relatively new and started considerably later than the 798 District. Secondly, whereas the 798 District today serves mainly as a place to sell and show art, the other districts consists mainly of studios and galleries and function thus as centres of production. Moreover, most other districts have lower rents and form a more inspiring surrounding for designers due to the lack of many tourists. It has been argued that 798 District and the other districts are complementary to each other where 798 District serves as the commercial and tourist hub to sell and show Chinese contemporary art while the others function as production centres producing art works that are sold in 798 District. This might be promising especially since 798 District is already a strong brand. However, as noted before it is argued that 798 sells more commercial art and real art fans do not go to 798 District. Moreover, Keane (2009) argues that creative clusters in China are developed by real estate developers in cooperation with the local government focussing on rising real estate prices. He states that culture in China is attached to economic development and that copying of original art works is the fastest way for success. The quality of Chinese art and barriers have been discussed in more detail in section 5. It might happen, that also other creative clusters develop from artist creative clusters to commercial creative clusters as it has happened in 798 District, and as it has been feared in the Hutong cluster. Rossister (2008) is also sceptical about creative clusters in Beijing and notes that in many of Beijing's creative clusters creativity has been placed in quarantine. $\mathrm{He}$ adds that 'there is rarely much creativity happening in the creative cluster' (p.123). 
The clusters described in this section are not the only creative clusters in Beijing. There are much more creative cluster and besides clusters focussing on aesthetical design, there are cluster with the focus on other types of design and other creative industries, including China (Huarou) Movie \& TV Industry Zone, Beijing DRC (Design Resource Cooperation) Industrial Design Creative Industry Base and China New Media Industry Base.

Based on the development of 798 District and the descriptions we have identified the major characteristics of the two types of creative clusters we have distinguished (see table 1).

Table 1: Characteristics of creative districts

\begin{tabular}{|c|c|c|}
\hline & Artist & Commercial \\
\hline Focus & Aesthetical value of art & $\begin{array}{l}\text { Commercial value by rising real } \\
\text { estate prices }\end{array}$ \\
\hline Function & $\begin{array}{l}\text { Design/production of art: } \\
\text { artist studios }\end{array}$ & $\begin{array}{l}\text { Sales and tourism: galleries and } \\
\text { exhibitions of arts }+ \text { secondary } \\
\text { tourism products }\end{array}$ \\
\hline Initiative takers & Artists and entrepreneurs & $\begin{array}{l}\text { Cluster managers on behalf of } \\
\text { land owners }\end{array}$ \\
\hline Customers & 'Real' art fans & (Mass) tourist \\
\hline Products & Art & 'Cheap/commercial art' \\
\hline \multirow{3}{*}{$\begin{array}{l}\text { Other } \\
\text { characteristics }\end{array}$} & Low real estate prices & High real estate prices \\
\hline & $\begin{array}{l}\text { 'Creative atmosphere' } \\
\text { informal gatherings and } \\
\text { networks, 'buzz' }\end{array}$ & $\begin{array}{l}\text { Direct or indirect control } \\
\text { district government }\end{array}$ \\
\hline & $\begin{array}{l}\text { 'untouched old places' (e.g. } \\
\text { old production plants, railway } \\
\text { storage buildings) }\end{array}$ & Upgraded areas \\
\hline
\end{tabular}




\section{Spatial Economic Conditions for Beijing's Design Sector}

This section discusses the spatial economic conditions for the development of Beijing's design sector. For this, we make use of the knowledge foundations that were identified by Van Winden et al. (2010), which are important competitive assets for cities in the knowledge economy. The knowledge foundations include: the economic base (the economic structure of a region), the accessibility of the region, the factor costs, the quality of life and the knowledge base (the knowledge infrastructure of a region and the labour pool). We apply these foundations exclusively to the creative industries and do not look to the other sectors in the regional economy.

\subsection{Economic base}

Creative and cultural industries are relatively new in China, as it was set on the political agenda in 2005 and one year later the City of Beijing explicitly paid attention to it. Nevertheless, the creative industries have risen quickly. In 2005, the cultural, sports and entertainment industries counted 215,000 jobs, which is equal to $3 \%$ of the total workforce (see Figure 1). Other key data of the creative industries show that the cultural industries employed 55,180 persons and obtained a business income of 186.76 billion RMB ( $€ 19.16$ billion) and made a profit of nearly 5.6 billion RMB ( $€ 574$ million) (see Table 2 ). The table also shows large differences between various cultural industries; some are highly profitable (for instance publication and copyright services), whereas others make losses (such as cultural, relaxation and amusement services) which is a common characteristic of the creative industries. It should be noted that the data in the table do not show all creative industries that are relevant for our study. For instance, it does not include architecture services and landscape design.

Beijing has some competitive advantages for the development of creative industries compared to other Chinese cities. First, as cultural and political capital of China it has a sufficient critical mass and economic diversity. Many of the people that were interviewed underlined the fact that one of the principal assets of Beijing is that it is China's capital city. This makes that the presence of the national and other governments is stronger than elsewhere and therefore also makes it easy for Beijing to find the financial resources to make the city 
attractive and dynamic. Moreover, the lines between the national government and the local governments are extremely short and therefore important decisions can be taken quickly and implemented efficiently. Its status as a capital city attracts also numerous headquarters of national and international firms, as well as providing it with facilities that can not be found in other cities, and therefore the right variety that offers the metropolitan ambience that he creative class requires. The city has various large economic clusters: financial services and the central business district in the city centre, High-Tech and ICT industries in the north-west around Tsinghua University; and the Olympic Green in the north as a major leisure district. The capital city is home to several headquarters of foreign companies, also because of government policies until the 1990's, large public and private firms were forced to locate their (regional) headquarters in Beijing (Chen, 2008). The city has also a wide variety of creative industries, such as movie production, fashion, art and architecture. All these creative industries are spatially concentrated in large clusters, despite the fact that the creative industries are relatively young. For instance, China (Huarou) Movie \& TV Industry Zone covers $5.6 \mathrm{~km}^{2}$ and it has 1,560 companies. Moreover, the capital attracts creative people and higher income groups. The presence of higher income groups is important for cities, since these are the major target groups for art. In relation with this, it is important to note that economic growth and the rising incomes have led to a growing art market. Finally, China's ambition to move up in the value chain by shifting the focus from mere production to creation (design) and production offers huge potentials for the design industries in Beijing.

Nevertheless, and despite the ambition to move up in the global value chain, the focus is still on production or copying original products. There are various reasons for this. First, the shift in focus takes time since there is a need to change skills which requires changes in training and the education system. Second, design and engineering are considered as equal and there is a lack to make a distinction between the two disciplines, which makes it difficult to focus on design. Third, there is a tension between originality and creativity which might lead to problems. For instance, Keane (2008) argues that the lack of content in China's animation industry forces business to fall back on manufacturing. Similarly, Van Winden et al. (2010) argue for China's automotive industry that since production is still profitable the need to make the decisive shift to higher added-value activities is limited. It is very likely that this is also the case in other sectors. Moreover, it is argued that in many creative sectors there is still a tendency to 
copy or to adapt original products, which remains highly profitable. Art and other forms of design are seen as commercial products that can be sold on the market and therefore design products in general are market oriented. In a similar way, many media industries imitate global successes in order to make profit and because financing, producing and distributing of original content is difficult (Keane, 2006). The tendency to duplicate original works and to focus on making profit can partly be explained by culture. China has a large population and people used to compete with each other instead to cooperate. For instance, trust among universities is low and in general universities do not cooperate with each other. Chinese people are individually driven and prefer setting up own business instead of cooperating with others. Furthermore, on the local level, people are used to live and think according their own system which differs from others and leads to competition. For instance, in China there are several museums which work with their own structure and according to own standards. This also explains why the clusters that we have described previously are loosing so many potential synergies that may stem from more intense collaboration.

There are positive exceptions of both foreign as well as Chinese galleries that also want to highlight the cultural aspects of art. Nevertheless, gallery holders, artists and other art institutes are confronted with the paradox between the desire to do non-commercial activities focussing on cultural value of art and the need to focus on commercial activities in order to survive. Especially in creative districts it seems to be hard to find a balance between commercial and creative activities. On the one hand, artists want to have creative surrounding without commercial activities and tourists; on the other hand tourists and business are needed to sell art works and hence to sustain artists financially. As noted before, the paradox between commercial and non-commercial activities is a common characteristic in many creative industries in all places of the world. A difference between China and many western countries, however, is the lack of a public system of financial incentives that help non-commercial activities to survive more easily and to help them stimulate creativity in general. 
Figure 1: Economic structure (permanent employment x 1000; 2005)

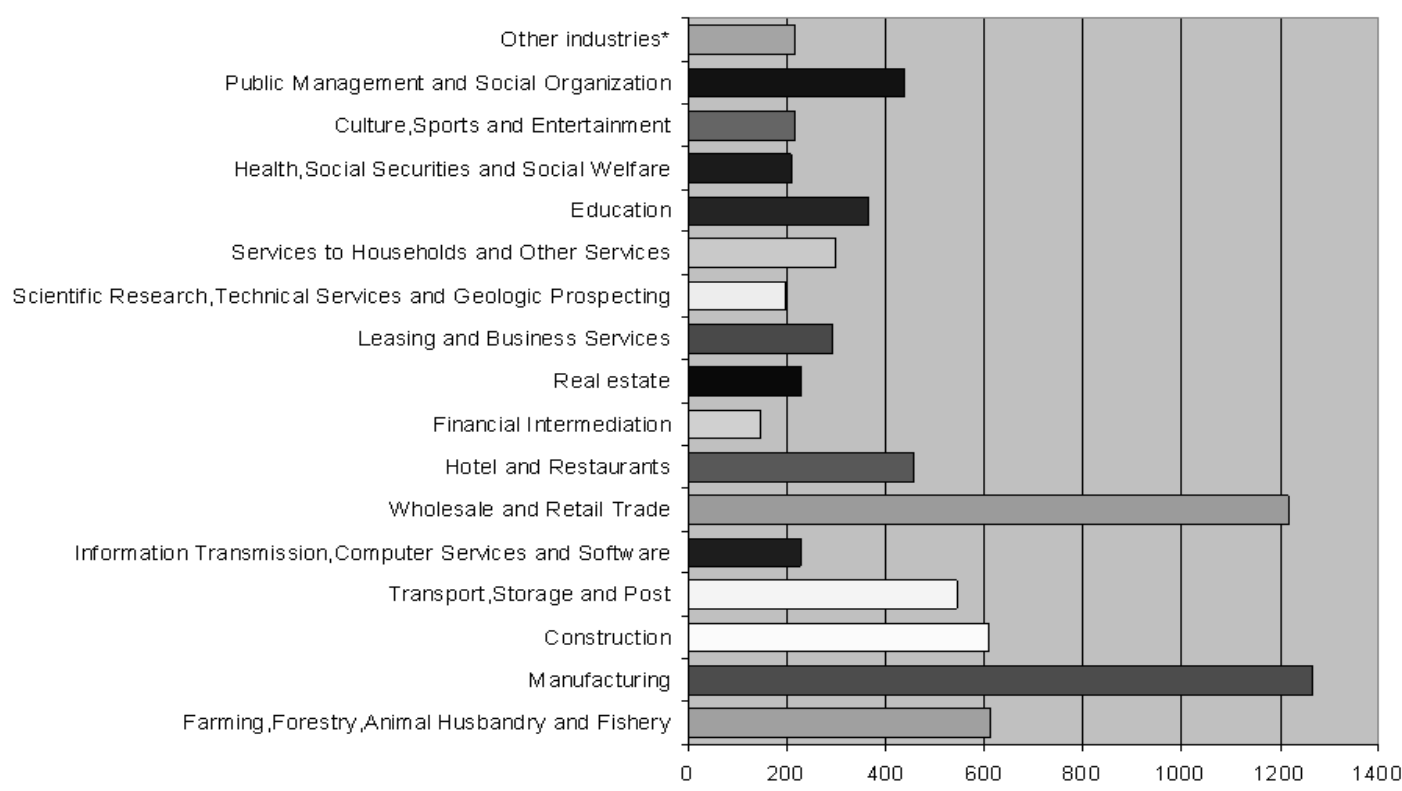

* Other industries include: Production and Distribution of Electricity, Gas and Water (84), Management of Water Conservation, Environment and Public Facilities (96), Mining (31), and International Organizations (4)

Source: Beijing Statistical Yearbook 2006, available at: http://www.bjstats.gov.cn/tjnj/2006-tjnj/index-english.htm

Table 2: Key data cultural industries (Million Yuan RMB; 2005)

\begin{tabular}{|c|c|c|c|c|c|}
\hline & $\begin{array}{l}\text { Persons } \\
\text { Employed } \\
(1000 \\
\text { persons) }\end{array}$ & $\begin{array}{l}\text { Total } \\
\text { Assets }\end{array}$ & $\begin{array}{l}\text { Added } \\
\text { Value }\end{array}$ & $\begin{array}{l}\text { Business } \\
\text { Income }\end{array}$ & $\begin{array}{l}\text { Total } \\
\text { Profits }\end{array}$ \\
\hline Cultural Services & 43.0 & 245918 & 34440 & 132948 & 5726 \\
\hline News Service & 6.3 & 6278 & 8.20 & 2141 & \\
\hline Publication and Copyright Service & 149.2 & 63363 & 10750 & 37914 & 2417 \\
\hline Broadcast, TV and Film Service & 34.6 & 58931 & 77.90 & 23046 & 1213 \\
\hline Cultural and Artistic Service & 49.4 & 18676 & 3140 & 6248 & -52 \\
\hline Network Culture Service & 29.5 & 20700 & 3630 & 9474 & 936 \\
\hline Cultural, Relaxation, and Amusement Service & 65.2 & 33515 & 2870 & 21196 & -185 \\
\hline Other Cultural Service & 95.7 & 44454 & 54.37 & 32928 & 1397 \\
\hline Related Cultural Service & 12.18 & 54529 & 4410 & 53815 & -127 \\
\hline $\begin{array}{r}\text { Production of Cultural Supplies, Devices } \\
\text { and Related Cultural Products }\end{array}$ & 61.0 & 20439 & 2420 & 9823 & -118 \\
\hline $\begin{array}{l}\text { Sale of Cultural Supplies, Devices } \\
\text { and Related Cultural Products }\end{array}$ & 6.08 & 34090 & 1980 & 43992 & -8 \\
\hline Total & 55.18 & 300446 & 38840 & 186762 & 5599 \\
\hline
\end{tabular}

Source: Beijing Statistical Yearbook 2006, available at:

http://www.bjstats.gov.cn/tjnj/2006-tjnj/index-english.htm 


\subsection{Factor costs}

As has been mentioned previously, China's economy in general and Beijing's in particular are still very much depending on the low costs of the principal production factors. Land rents are low, labour costs are low, and the prices of some of the primary inputs that can be found in China are still low. However, pressure on the factor costs is rising and the awareness has risen that the competitiveness of the industry con not infinitely rely on factor costs being low. In fact, efforts are being made to shift towards more profitable production processes and to move upwards in the global value chain. This tendency, as we have seen before, may particularly benefit the Chinese design sector.

\subsection{Accessibility}

Accessibility is a key factor in the knowledge economy in which actors increasingly work in networks. This is especially true for the design industries where many business are done in projects. As a capital city, Beijing has a large international airport with many linkages to many other major cities in the world. This is especially important for design industries that are engaged in projects worldwide, such as international architect firms. Nevertheless, being a big city has also some major drawbacks, for instance in the form of the daily traffic jams that hamper access. In order to limit congestion and to reduce air pollution, the city government has extended and improved public transport considerably over the last decade, also in occasion of the Olympics. The process continues. The length of the subway network will be extended from $260 \mathrm{~km}$ nowadays to $560 \mathrm{~km}$ in 2015. Furthermore, a low tariff has been used to make public transport more attractive and to prevent exclusion of low income groups. A subway ticket costs 2 RMB $(€ 0.21)$ per trip, independent of the length of the trip. Another measurement to improve public transport and to fight congestion is by the construction of special lanes for busses. Nevertheless, due to rising incomes, car ownership rises quickly and since cars are seen as a status symbol congestion increases. Moreover, in the interviews it has been argued that car transport has given priority at the costs of pedestrian and biking zones. This stimulates car usage at the cost of other transport modes. 


\subsection{Quality of life}

Despite various critiques in literature (e.g. Peck, 2005; Scott, 2006) the quality of life has been considered as a key factor to attract the creative class (Florida, 2003), especially among policy makers. The perceptions about the quality life and the status of Beijing as a creative city are mixed. On the one hand, Beijing is a true capital city with several characteristic urban amenities that attract knowledge workers, such as bars, museums, restaurants and theatres, and according to our interview partners many creative talents live in Beijing for this reason. Moreover, different places in the city are mentioned as vibrant and inspiring, which is an important condition for many creative industries. Especially the 'hutong cluster' has been considered as having the right atmosphere for many creative industries. On the other hand, there are also some doubts about the status of Beijing as a creative city. One of our interview partners noted that Beijing is not as inspiring and vibrant as it could be, especially when compared with cities as Shanghai and Hong Kong. Moreover, many interview partners, foreigners as well as Chinese, agreed that bureaucracy is a major barrier for creativity and lowers the living and working conditions.

Another negative factor on the quality of life is (heavy) air pollution, which makes the city less attractive than other global cities. The air pollution is the major concern for the Beijing Municipal Environmental and Protection Bureau and the City of Beijing has already spent 140 billion RMB $(€ 14.36$ billion) in programmes to improve air quality. Programmes include both practical measures, such as washing the wheels of trucks that leave construction sites, as well as more sustainable solutions such as the use of sustainable design and educational programmes aimed to stimulate sustainable behaviour. Sustainable design includes the use of sustainable materials in new buildings and construction of innovative buildings that use clean energy. Currently, there are three sustainable buildings in Beijing, among which a building at Tsinghua University and a building of the Ministry of Environmental Protection. A drawback, however, is that although most actors are aware and willing to use for sustainable solutions, competition forces various actors to choose for unsustainable options. Another factor that hinders the reduction of air pollution is the quick development of Beijing and other parts of China. Increasing income leads to increasing consumption (including more cars that have become a status symbol) and production which makes it difficult to reduce air pollution. 


\subsection{Knowledge base}

A good knowledge base is a major condition to develop industries further and to move to higher valued activities in the value chain. As a capital city, Beijing has several universities, public and private research centres and educational facilities. The city has at least two institutes specialised in creative industries that are among the best in China. First, the Central Academy of Fine Arts (CAFA) is an art school that is assumed to be the best in China. The centre is very selective and takes only the best students. It plays a major role in developing talent. Via exhibitions that are funded by venture capital, talent is given a chance to show their works. The second major institute is Tsinghua University, one of the top schools in architecture and planning. In addition to the Chinese institutes, Beijing attracts also many foreign institutes. For instance, a branch office of Columbia University intends to locate in the one of the central Hutongs, which is seen as a particularly attractive location because of its inspiring surroundings. It should be noted that also other cities in China have major institutes that may sustain the creative industries, such as the Tongji University in Shanghai, a leading school in architecture and planning.

Besides specialised research schools and training centres, there are also other ways to improve the knowledge base and to increase the knowledge level in a region. Firstly, companies can improve the labour pool and attract talent via various strategic actions and programmes. Especially foreign companies can play a major role in this, since these companies have a longer tradition in contemporary art and design, which is still relatively new for many Chinese companies. The perceptions about this are mixed. We have seen examples of foreign companies that provide several activities to train students and cooperate with local education institutes. These companies provide internships, organise summer courses and give guest lectures at universities and thus aim to contribute to a better knowledge base. However, during the interviews it was also argued that especially famous design companies could do more to transfer their knowledge to local actors in stead of doing only big projects. Second, Chinese companies can learn from abroad via study trips to major projects abroad, such as (re)development projects and exhibitions. A third way to gain knowledge is via training students abroad who return to China after their study in order to set up their own design school or to start their own companies. For instance, the Design School of the University of Art and Design (UIAH) in Helsinki attracts 
many Chinese students (from bachelor to PhD level) who return to China to work as designer after receiving their degree. Nevertheless, in our interviews it has been argued that Chinese students who return form abroad face problems in applying their obtained knowledge due to the social and institutional barriers. They need to focus on the commercial value of art, although they are aware of the aesthetical value.

In spite of the presence of key knowledge institutes and strategic actions of firms to improve the knowledge base, the pour level of the education system has been perceived as a major drawback for further upgrading and development of the creative industries. All our interview partners agree that the educational level is low and that there is a need to change the education system. Art education has already changed. In the past, art education was limited to teaching classical Chinese art with silk and ink as major products, and the focus was on socialist realism. In a later stage, also the European Expressionism and Impressionism had been added in the educational programme. Nowadays, education has been more updated with more influences from outside China and pupils have more freedom than in the past. Nevertheless, the education system is still very hierarchical and students are expected to listen to the teacher, leaving little room to express own ideas and to develop creativity. As a consequence, designers lack own ideas and originality. Mars (2009) notes the same and states that there is an absence of good designers due to a lack of good design education. This is a serious hurdle for the development of Chinese cities. A related barrier to develop own ideas is the focus on commercial values which increases the tendency to copy products which are sold against low prices instead of making original works. This is also a major barrier in the education system. From our interviews it has become clear that in the education system the focus is still in developing skills to sell art instead of creating it. So, there is a need to embed creative processes in the education system, to get rid of the idea that quantity of production equals to economic value (Keane, 2006) and to pay more attention to aesthetical values of art.

\section{Urban design}

Design plays a major role in urban development in various fields. First, urban design (including architecture and landscape design) is crucial for physical development of the city. Design plays also a role in social development, 
development of infrastructure and in sustainable development (e.g. reduction of air pollution). In this section we analyse the role of design in these fields in more detail.

Architecture plays a key role in the physical and symbolic development of a city. Since the Cultural Revolution, architecture in Beijing has evolved in various stages. First, in the 1970's and the 1980's, the period after the Cultural Revolution, a new period started in which the focus was to build a new and modern city. Many low quality skyscrapers were built in that time and cultural heritage was simple destroyed. The towers conserved Chinese identity through ancient roofs which developers were forced to build via a special rule. This explains why many towers still have ancient roofs nowadays. It should be noted that in the end of the first period, the level of design improved and better buildings were being built. In the second period, mid-1990's to the Olympic Games in 2008, the focus was on modern, western design. Leading up to the Olympics, Beijing's 'famous' Gang of Five foreign architects, Koolhaas, Holl, Andreu, Herzog \& de Meuron and Foster were invited to design modern landmarks, such as the CCTV Tower and the national opera (Muynck, 2008). After the Olympics, the state stopped the attention on foreign architecture, and in the current period, there is the belief that China can design modern architecture without foreign support. Some Chinese architects have even entered international markets, with MAD's Toronto Towers as best practice up to now. This latter stage is characterised by a mixture of foreign and Chinese design and it is difficult to distinguish Chinese from western design. Moreover, there is a shift in focus from the aesthetical aspects of buildings to functionality. In addition, attention to build in an environmental friendly way has started. This is all caused by a change of taste from the government. Nevertheless, it should be pointed out that Chinese architecture has improved a lot in terms of sustainability and safety, but it is not on the optimum stage yet. China succeeded in designing safe buildings, but it still needs to make progress in creating buildings taking into account a safe and clean environment. There are also doubts about the quality of Chinese architecture design. First, there are questions about the quality of the design consultants in various stages. Second, there are doubts about the export opportunities for Chinese architects. It has been feared that many low quality architects will enter the international market after the success of MAD in Toronto. Furthermore, it has been argued that MAD won the project in Toronto also because of the experience of the European designers who worked for the 
company in that time. Other Chinese firms may lack foreign experience and knowledge.

Culture and cultural heritage have also played a major role in the development of Beijing. Beijing was set up along a vertical axis according to Confucius' believes. In the development of the Forbidden City, the front was placed to the south to catch the full noon sun, while the north faces 'darkness' (Tan, 2005). Nowadays, this vertical axis is still the major central line of the city, and most cultural attractions are located along this axis that runs from the Olympic Green in the north to Temple of Heaven in the south. Culture is a cause of various periods in architecture and influences cultural heritage. About twenty years ago, the government did not pay attention to cultural heritage for economic and cultural reasons. First, due to low labour costs it is more efficient to demolish old sites and to construct new buildings from scratch than to renovate buildings and sites. A second reason is related with culture. One aspect of the change of dynasty, the turn to another period, is the building of new elements and to forget the previous period. There is in this ideology no reason to keep elements from previous periods. Foreign as well as local architects pointed at the importance of keeping old heritage, and nowadays also the Chinese government realises that certain parts of the past need to be conserved.

Design plays also a major role in sustainable development and in the reordering of public space, which gained both particular attention in Beijing in the preparation for the Olympic Games. Just like in many other cities that hosted the Olympics in the past, Beijing did not only use the Olympics to get media attention and to build landmarks. The mega event has also been used for urban development and to promote and apply sustainability. As noted before, various districts in the city, such as 798 Art District, were regenerated and improved to receive visitors. Moreover, the event played a key role in increasing the awareness of sustainability and the environment among the public. Many actions that were taken for the Olympics, aiming at stimulating liveability and sustainability, continue after the games. One example is the 'one-day-driveless programme' in which car owners are required to drive one day a week less. Based on a combination of the number plate cars cannot drive on a certain day in the week. This is absolutely necessary, since car ownership rises quickly, with about 1000 new registered cars per day. The Olympic venues themselves are also important to realise a green city. The venues are constructed with environmental friendly materials and buildings are designed in such a way that the amount of 
incoming natural light has been maximised in order to save energy. Thus in this sense, urban design plays a key role in developing the city in a sustainable way and to bring the city in harmony. Beijing Municipal Environmental and Protection Bureau, responsible for monitoring and implementing environmental standards, has learned a lot from the games and aims to continue the thought of the green Olympics. Among policy makers and society, there is awareness and willingness to develop a green city, but there is also awareness that there is still a long way to go to do that.

Furthermore, design plays a key role in development of tourism and in social development. First, modern architecture and attractions, such as Olympic venues, could be used to diversify the tourist product and to attract new target groups which are also interested in modern attractions. However, currently, the follow-up of the Olympics faces problems as many Olympic attractions and spaces are seen as a burden rather than an asset. In its current tourism strategy, the city aims to converge traditional with modern attractions, to combine traditional cultural elements with tourism and to increase variety in the tourist product. The ultimate goal is shift from quantitative to qualitative growth in order to increase the value added of tourism. Second, design has been used to solve practical problems due to peaks in the tourism flow creating pressure on the facilities. For instance, on Labour Day, the busiest day of the year, over 120,000 visitors visit the Forbidden City. Practical tools that have been used in the Forbidden City are: signposting in one direction, an extension of the number of employees who protect the attractions, and an increase in the number of drinking points. Besides these practical solutions, in which design plays a key role, the city also uses other measures to fight the peaks in tourism flow, such as the use of price differentiation. Third, design has been used to conserve and to upgrade traditional areas that are targeted as tourist attractions, such as certain selected hutongs. Hutongs are old Chinese neighbourhoods with small houses and narrow streets. Originally, these houses were constructed for one family, but Mao decided that the houses needed to be shared among four families. This decreased hygienic and living conditions considerably. The Cultural Revolution was seen as a new stage and new flats were built by state designers, or at least according to standards given by the state. There is a sort paradox between the urban and social structure of the old hutongs and the modern (sub)urban areas. One the one hand, the new apartments have a higher quality and better living standards (larger size, and modern facilities like warm water) than the hutongs, but lack the common spaces as the hutongs 
had on the streets which functioned as meeting places. It seems to be impossible to keep the urban and social structure in the new flats. However, nowadays, various foreign as well as domestic design companies have designed conceptual plans for old hutong areas that mix various functions, such as tourism, culture and retail and aim to conserve public spaces as far as possible.

Another field where design plays a role is (public) transport. As noted before, in order to fight congestion, the subway network has been extended extensively. In the past, station and subway development was done by a special institute and design played only a limited role. Nowadays, design plays a major role for development of some new stations. There are open competitions to design and develop new plans. This has increased the quality and stations have a higher aesthetical value. A major drawback, however, is the lack of adaptive design of the subway system. The system is based on applications that have been developed for the use in Hong Kong and in Shanghai, without the adaptive development to local usage which has led to practical problems. One is the ticket purchasing machines, which has been developed for Shanghai where coins of one Yuan RMB have been used, whereas Beijing exclusively uses notes of one Yuan RMB. This has led to an extra handling, money exchange, which may lead to queuing during the peak hours. In general, Beijing does not make a distinction between hardware and software. Hardware can be transferred easily across distance, whereas software needs to be adapted locally. Another major drawback is that Beijing is developing itself as a car oriented city. Roads have been broadened, while the space for pedestrians and cyclists continues to decline. The idea is that increased road transport leads to further leaps in economic development. This is also caused by an element of the Chinese culture, where happiness is defined as earning more money rather than living more comfortably. The one-day-drive-less programme is not considered as a sufficient tool to fight pollution. Some even argue that it will lead to extra traffic since people are tended to buy a second car to avoid the rule.

\section{Aesthetical design}

Aesthetical design has value for cities when it is used to improve attractiveness of public spaces and buildings, or when it can be shown and sold in cities. A key development for the latter is the quick rise of the contemporary art and fashion 
markets. Several foreign, and in a later stage also Chinese galleries, have been opened showing foreign as well as Chinese art works. Contemporary art is relatively new in China, but the number of galleries and customers rises quickly and the potential is high. Until the 1990's, there was strict censorship and contemporary art was created and sold in informal networks, which often took place outside the city centre (Rui, 2008). Before the year 2005, only foreign galleries showed contemporary art. Since that time, also Chinese people have got interested in creating and showing it. A major cause for the quick rise of the contemporary art market is the rising middle class in China which have a broader understanding of art and more time and income to spend on art. In the past, for the majority of the Chinese people, knowledge of art was limited to traditional art, while contemporary art was unknown. Moreover, it was not common to spend free time on (visiting) art and cultural activities (like museums and galleries) which may be explained by the education system which does not teach what the aesthetical value of art is.

Despite, the quick rise of the Chinese contemporary art market, there are some barriers that might hinder further development of the contemporary art market as well as growth of other design industries. First, there is too much bureaucracy. Galleries need to ask permission and pay a fee for holding an exhibition at least three months in advance. It was even argued that for Chinese art projects more than three months in advance at least 10 documents need to be filled in giving an entire documentation about what will be shown. Foreign work needs to be arranged even earlier and all details about the art works and the organisation of the exhibition needs to be arranged in a very early stage. Furthermore, there are many limitations for the works shown, and the government has an influence on what can be shown. It should be noted that there are also art forms permitted in China which are not common and prohibited in the west for ethical reasons, like death bodies and animals. In sum, organising exhibitions have been perceived as a complicated and time consuming process and it is seen as a risky investment.

Similarly, also architects face the regulations as a barrier that hinders creative freedom and work. In contrast to the projects in the west, and in contrast to the organisation of exhibitions, the restrictions at the beginning of the architecture design process are limited, giving much freedom to architects. However, during the process many limitations are given by clients. This leads to many adaptations of the ongoing project, and in the end, many elements of the first idea have 
disappeared. It should be noted that some interview partners do not agree and argue that it is possible to make clear agreements at the beginning of the architecture design process. The different views might be explained by the role of the different players in the architecture design process. Actors which focus on aesthetical aspects of architecture might have more reasons to complain than other actors. It should also be pointed out, that architecture in general, in all parts of the world, has been confronted with more safety, environmental and regulations that limit the creativity.

A second barrier for further development of design industries is the tendency to copy designs (see also section 3). Art is often still based on many similar styles and copying of other works with limited adaptations. This holds true for various types of design industries; many art objects in public spaces are replicas of other works, just like paintings in galleries and the architecture of buildings. For instance, architectural bureau $Y$ recognised its work in at least two other places in Beijing and even in a city in another part of China. Moreover, there are doubts about the quality of Chinese design. For instance, many new buildings look nice from the outside, but have a low quality due to the overall use of cheap materials.

Another, related drawback is a general shortage of financial resources, especially for the contents and the programming rather than for the initial investment. With exception of the national museum, which receives high political support, many museums have a shortage of financial resources for their functioning. Therefore, museums start to diversify their activities, opening restaurants for example, or stay empty. One example is a city in northeast China which constructed a new one billion Yuan RMB ( $€ 0.1$ billion) costing museum but that still does not have a collection. It is argued that the museum has mainly been constructed for governmental reasons to build a landmark. A strategy that has been used to overcome financial deficits on non-profit activities is to create cross-over effects between commercial and non-commercial activities. This strategy has been used by public-private as well as by completely private companies and is done by Chinese as well as by foreign companies. Public-private actors do not necessary get direct financial support for non-commercial activities, but can also be compensated via other forms of support, such as information exchange, special treatments and tax relieves. 


\section{Governance and policy}

Design and other creative industries are seen as key priorities for the state as well as for the City as Beijing as both have officially put it on the national respectively local agendas in 2005 respectively 2006. The State has positioned Beijing as 'the capital as well as the political and cultural centre of China' and the municipality of Beijing expresses that 'culture is a critical guarantee of economic development as well as an important goal of social development', and thus 'Beijing should develop cultural industries actively and make it a pillar of Beijing's economy' (Hui, 2006). However, there seems to be a lack of financial support, since unlike in other places like Britain, China has no state funding programmes for 'creative entrepreneurs', designers, artists and intermediaries (Rossister, 2006). Nearly all our interview partners agree on the need to develop a subsidy system to support creative industries, to stimulate the aesthetical value of design when the commercial value is still modest, and to give support to those who are interested in adding content to cultural programmes and ideas.

The political structure and elements of the Chinese culture have influences on urban development and the governance and development of creative industries such as design. Major elements that characterise governance in China are: hierarchical relations (top-down decision making and control), public landownership and 'guanxi'. Guanxi refers to personal relations with the appropriate authorities or individuals (Yeung and Tung, 1996). This has various implications for designers. First, in order to show art in public spaces, artists need to know the right persons or to pay a considerable fee. Similarly, also the place where to show art works, in private galleries or in public spaces, is dependent on the personal network of artists. Second, designers are confronted with censorship and bureaucracy that might hinder development of creative industries and decreases creative freedom (see also section 5). Third, as noted before, and especially in clusters, there are many informal networks, while formal cooperation with other companies is limited. This is a common characteristic for many creative industries, but in the interviews it was also noted that cooperation with other companies is limited for cultural reasons. In contrast to Europe, formal cooperation is not natural in China and happens only incidentally. This is one of the reasons why potential synergies and agglomeration economies are emerging less frequent than they could in the design clusters. 
It should be mentioned that many architectural companies have (formal) relations with the Beijing Institute of Architectural Design (BIAD), a large state-owned architectural design and consulting institute. Some of the interview partners have personal relations with BIAD, but it might also be that many architects cooperate strategically with BIAD for political reasons. Fourth, the political structure and cultural aspects have implications on the master plan (see Box 1) and on spatial planning in general in which both (urban) design plays a key role. For instance, regarding transport infrastructure, the city of Beijing faces problems to make a distinction between hardware and software (see also section 4) due to the administrative structure of the city. Just like in many other countries, building and operation of infrastructure has been done by different actors. Furthermore, the operation of different transport modes (rail, road, subway and air transport) have been done by various departments. The city faces problems in coordinating these different departments, because horizontal relations are limited. This hinders development of infrastructure in two stages (build hardware and adaptation of software). Furthermore, plans change rapidly. Actors involved in implementing the plans get new information that is provided top-down, often in a late stage and have limited influence on the plans. Similarly, there are several plans to improve the quality of public spaces which are difficult to implement due to institutional barriers. There are many actors involved in the plans, which are top-down steered without horizontal relations. In addition, there are two types of 'sectors': grassroots ('private-spontaneous') and government-led (see section 2). Especially before the year 2000, several conflicts existed between the two sectors due to different interests. For instance, Yuanmingyuan and Dong Cun were two creative clusters that were demolished by the government because the government did not see the value of these activities. It should be noted that this changes gradually; the government acknowledge the relevance of the creative industries and the interests of the two sectors increasingly seem to divergence, although there are still some major differences in interests as the case of 798 District shows.

It is worth noting that the political structure might also have advantages. For instance, the top-down structure increases the speed of decision making and major programmes, such as programmes to reduce air pollution, can be implemented quickly. Another advantage might be what Chen (2008) calls the 'socialist-capital effect' referring to the locational advantage of having direct access to decision makers of foreign 
companies that were forced to set up regional headquarters in the capital.

Box 1: Master Plan Beijing

The Master Plan of Beijing consists of two parts: the broad master plan it selves and detail plans. Within the detail plans, small adaptations are possible like the (re)location of small companies. Several actors are involved in the planning process: The National and Reform Commission ('the development ministry'), the Construction Ministry and Land Management. The Land Management has contact with users of the land (such as artists or gallery holders), which happens via special offices that are open to the public and via the development of drafts which are open for users (for instance via the internet).

The development of the plan is top-down driven. The ideas of the top level are the most important, while the ideas of the lower level need to fulfil the requirements of the top level. Regarding grassroots developments, the initiative takers of new plans/developments have a relatively weak position, since they do not own the land. They have the right to rent it and have limited influence on developing the land for certain purposes. Private ownership does not exist in a comparable way as it is known in the west. The real estate is in ownership, while land cannot be owned. Only people with the right networks can have real estate in ownership. This ownership is temporary (about 70 years) and assets need to be handled back to the state after this period.

In the planning process, there is not one actor which dominates. It differs per project which governmental body or other actor has the power. For each plan, there is a trade-off between the interest of two departments: the Planning Department (responsible for zoning policy) and the Land Management (which has the right to rent out the land). Planners and real estate companies have limited power. They need to fulfil requirements set by the Planning Department. Based on these requirements planners can make a plan and design. They have limited possibilities to change the plan.

The development of international networks is important to exchange information and to gain knowledge. For instance, China stimulates (PhD) students to do a study abroad in order to bring new knowledge to China (see section 3 ). There are also various cooperation programmes with specific countries. One example is the 'Sino-Italian Cooperation Program for Environmental Protection', a cooperation programme between Italy and China aiming to help China to improve her 
environment, support her sustainable development and promote the cooperation between enterprises of the two countries. This programme has several projects in which design plays a major role. For instance, a sustainable building at Tsinghua University is a project under this cooperation programme. It is worth mentioning that the cooperation programme is national, but implementation of projects often takes place at the local scale.

\section{Conclusions}

The case of Beijing shows first of all that the emphasis laid on the role that the creative industry can play for urban development and for urban revitalization is not exclusively reserved to post-industrial economies and cities. In fact, from 2004 onwards, the development of cultural clusters has been one of the priorities of the Beijing administration. However, while leading cities in Europe are focussing very much on service or social design, the capital city of China is still investing in design as a form of art and in urban design. This last aspect is probably caused by the fact that the city hosted the Olympic Games as recent as in 2008, and because of the Games the whole city, including the public space, has been extensively overhauled. In that occasion, an impressive number of modern iconic buildings have been added to Beijing's skyline.

Less relevant is also the role that industrial design and creativity can play in upgrading the Chinese manufacturing sector. Much of the competitiveness of the Chinese industry is still based on the low factor costs, in particular labour and land. Moreover, simply copying successful concepts from American, European or Japanese firms is still widespread. The awareness that this comparative advantage may not last indefinitely, has led to a shift in the focus and a search to move upward in the global value chain, engaging in higher value-added activities. Very recently, indeed, the government has started to underline the importance of defending more intensively the property rights or the intellectual components in manufacturing.

The principal asset of Beijing is the fact that it happens to be the capital city of Modern China. The presence of the national and other governments is very strong and therefore the financial resources to make the city as attractive as possible are available. Moreover, the lines between the centralist 
national government and the local governments are extremely short and therefore important decisions can be taken quickly and implemented efficiently (it might be one of the very few examples where the infrastructure necessary for the Olympic Games was in place long before the opening day). Its status as a capital city attracts also numerous headquarters of national and international firms, as well as providing it with facilities that can not be found in other cities, and therefore the right variety that offers the metropolitan ambience that he creative class requires.

Being one of China's historical capitals, Beijing has a long tradition in both aesthetical as well as urban design. It still is, especially for a Chinese city, still rich of cultural heritage and monuments. The increasing attention for modernity and contemporary arts has made the city invest in modern buildings, up-to-date facilities, futuristic stations and airports, and high-quality public areas. It has, however, meant that the traditional neighbourhoods (hutongs) were being sacrificed to make space for modernity. Only recently, the respect for more popular forms of cultural heritage other than the Forbidden City and the Summer Palace, has grown.

This particular mixture of traditions and modernity is now seen as Beijing's potential selling points. In fact, the challenge to transform these aspects of the Chinese capital in one unique product, also with respect to the tourism market, has now been identified as fundamental for the city's future. Here, service design, that is finding the right organisational solutions for solving some of Beijing's structural problems, such as pollution and congestion, might play an interesting role.

Beijing's competitiveness as a creative city are based on some strong foundations. Its economy is very diverse in structure and the critical mass of the economic base is enormous. Factor costs are still low, but are on the rise, a tendency that might endanger the industry's competitiveness the next years. Beijing is very rich of R\&D institutes and of knowledge and education centres. Its external accessibility is guaranteed by a modern international airport. Internal accessibility might be better if the extensive subway network was designed closer to the inhabitants' needs and used more intensively. Due to the presence of top class facilities, the quality of life is rather high, but would be even higher if the structural and interrelated problems with pollution and congestions would have been tackled more effectively. 
An increasing awareness for sustainable development and the willingness to invest in it offers major opportunities for the growth of the urban and service design sectors. The growth in the average income per head of the population has caused the market for arts and design to expand, an expansion that is expected to continue the coming decade. Last but not least, the desire to move upwards in the global value chain, shifting gradually from a low cost concept to a high contents and value added idea of manufacturing will offer huge opportunities for industrial designers.

In order to use these potential fully, some important barriers have to be removed. First of all, the education system has to be changed, gradually teaching students to become more critical and autonomous. This is, given the present political system where individuality is not much appreciated, not as easy as it may sound. Secondly, more value should be attributed to originality and less to duplication. At the moment the market does not attribute enough commercial value to originality and hence copying continues to be a wining strategy. This makes Chinese architects and designers very vulnerable to international competition. The existing creative clusters in Beijing are under pressure because of their own success. Land rents are rising and the market forces artists to focus either on commercial activities or leave the cluster in search of cheaper accommodation. The introduction of some control over land rents or a system of subsidies for non commercial forms of creativity seems unavoidable. A third hindrance for the further development of Beijing's creative industry is the weight of bureaucracy and in some cases of censorship. The tension between spontaneity and grassroots development and planning and intervention that characterises also European creative clusters is definitively penalising the creative industry in China and Beijing.

This automatically brings us to the following policy recommendations, some of which we are aware of are difficult to pursue in the short run:

- Maintain and upgrade more popular cultural heritage and traditions, such as the hutongs, because they form a unique environment that attracts families and firms on which urban innovation is based. The main challenge is to find and maintain the right balance between the old (living area and community places) and new functions (tourism, leisure, commercial activities, etc); 
- Gradually change the education system, giving more freedom to students and emphasise the positive role creativity might play;

- Enforce the relationship between universities and the industry, for example embracing the 'Smart Cities' programme in the UK as a best practice;

- Introduce financial support for the creative industries not only paying for the hardware in creative clusters but financing also the necessary software and orgware. Moreover, a subsidy system needs to be created to maintain the non commercial activities in the creative clusters, activities that are of an essential importance as continuous sources of inspiration for the commercial layer of the creative industry;

- Decrease the level of bureaucracy with respect to artists and creativity. They are incompatible everywhere and not only in China;

- Introduce educational schemes and render (modern) art a public good: show art on streets and in museums and make private investors contribute to the quality and originality of the environment they are investing in;

- Review the post-event function of the buildings and the space that has been constructed in the Olympic area. Its present underutilisation harms the continuity of the area. This area is particularly suited to host creative activities and cultural events. One of the many suggestions that were put forward during our visit was to establish a fashion museum on the Olympic premises.

It is obvious that our view on the creative industry in Beijing is very much a Western one. Cultural differences influence the conclusions that we have arrived at as well as the suggestions for policy that we have come up with. Nevertheless, and notwithstanding these cultural differences, it is fascinating to see how similar Beijing's awareness of the potential contribution of the creative industry and the different forms of design can give to urban development, and how much emphasis is given to creativity and design in a city that is still very 
much an industrial powerhouse of the world and does not need to diversify as urgently as many European cities.

\section{References}

Chen, K. (2007), The Rise of China's Contemporary Art Market, School of the Art Institute of Chicago Arts Organizations in Society, online available at: http://www.saic.edu/pdf/degrees/pdf files/aap/2007 Kelly Che n.pdf (Downloaded 22 April 2009)

Chen, Y.C. (2008), Why Do Multinational Corporations Locate Their Advanced R\&D Centres in Beijing?, Journal of development studies, Vol. 44, No. 5, pp. 622-644

Florida, R. (2003) The Rise of the Creative Class. New York: Basic Books

Holz, A.H. (2008), China's Economic Growth 1978-2025: What We Know Today About China's Economic Growth Tomorrow, World Development, Vol. 36, No. 10, pp. 16551691

Hui, D. (2006), From cultural to creative industries - Strategies for Chaoyang District Beijing, International Journal of Cultural Studies, Vol. 9, No. 3, pp. 371-331

Keane, M. (2006), From made in China to created in China, International Journal of Cultural Studies, Vol. 9, No. 3, pp. 285-296

Keane, M. (2009) Great adaptations: China's creative clusters and the new social contract, Continuum: Journal of Media \& Cultural Studies, Vol. 23, No. 2, pp. 221-230

Mars, N. (2009) How to produce good architects?, Urban China, No. 35, January 2009

Munck, B. (2008) How foreign architects became international architects, Urban China, No. 33, December 2008

Munck, B. (2009), Architecture on the move: Urban and architectural design in Inner Mongolia, Continuum: Journal of Media \& Cultural Studies Vol. 23, No. 2, pp. 209-219 
Pasternack, A. (2008), Other kinds of ambitions: From Artist villages to art districts, Urban China, No. 33

Peck, J. (2005) Struggling with the creative class, International Journal of Urban and Regional Research, Vol. 29, No. 7, pp. 740-70

Porter, M.E. (1998), Clusters and the new economics of competition, Harvard Business Review, November-December 1998

Rossiter, N. (2006), Creative Industries in Beijing: Initial Thoughts, LEONARDO, Vol. 39, No. 4, pp. 367-370

Rossiter, N. (2008), Countermapping Creative Industries in Beijing (Introduction), Urban China, No. 33, December 2008

Rui, H. (2008), Reflections on 'Factory" of Art - Beijing 798, Chengdu: Sichuan Fine Arts Publishing House, 2008.6

Pratt, A. and P. Jeffcutt (209), Creativity, Innovation and the Cultural Economy, Routledge: Abingdon, Oxford

Scott, A.J. (2006) Creative cities. Conceptual issues and policy questions. Journal of Urban Affairs, Vol. 28, pp. 1-17.

Storper, M. and A.J. Venables (2004) Buzz: face-to-face contact and the urban economy, Journal of Economic Geography, Vol. 4, pp. 351-370

Tan, L. (2005) "Revolutionary Spaces in Globalization: Beijing's Dashanzi Arts District." Hybrid Entities. Intersections Conference Journal - Graduate Student Conference of Ryerson/York University. March 2005. (Downloaded 22 April 2009 from http://www.yorku.ca/topia/docs/conference/Tan.pdf)

Van Winden, W., L. van den Berg, L. Carvalho, and E. van Tuijl (2010, forthcoming), The role of manufacturing in the new urban economy. Routledge: Abingdon, Oxford

Yeung, I., \& Tung, R. L. 1996. Achieving business success in Confucian societies: The importance of guanxi (connections). Organizational Dynamics, Vol. 25, No. 2, pp. 54-65. 